Article

\title{
Heuristic Optimization of Culture Conditions for Stimulating Hyper-Accumulation of Biomass and Lipid in Golenkinia SDEC-16
}

\author{
Changliang Nie ${ }^{1,2}$, Liqun Jiang ${ }^{1,2}$, Qingjie Hou ${ }^{1,2}$, Zhigang Yang ${ }^{1,2}, \mathrm{Ze} \mathrm{Yu}^{1,2}$ and \\ Haiyan Pei 1,2,3,* \\ 1 School of Environmental Science and Engineering, Shandong University, Qingdao 266237, China; \\ nwei@sdu.edu.cn (C.N.); ljiang@sdu.edu.cn (L.J.); qingjiehou@sdu.edu.cn (Q.H.); \\ 201912714@mail.sdu.edu.cn (Z.Y.); yuze3558@gmail.com (Z.Y.) \\ 2 Shandong Provincial Engineering Center on Environmental Science and Technology, Jinan 250061, China \\ 3 State Key Laboratory of Microbial Technology, Shandong University, Qingdao 266237, China \\ * Correspondence: haiyanhup@126.com; Tel.: +86-531-88392983
}

Received: 24 January 2020; Accepted: 14 February 2020; Published: 21 February 2020

check for updates

\begin{abstract}
Overproduction of biomass and hyper-accumulation of lipids endow microalgae with promising characteristics to realize the cost-effective potential of advanced bioenergy. This study sought to heuristically optimize the culture conditions on a rarely reported Golenkinia sp. The results indicate that Golenkinia SDEC-16 can withstand the strong light intensity and grow in a modified BG11 medium. The optimal culture conditions for the favorable tradeoff between biomass and lipid accumulation were suggested as follows, 25,000 lux of light intensity, $9 \mathrm{mM}$ of initial nitrogen concentration, and $20 \mathrm{mM}$ of initial sodium chloride concentration. Under these conditions, the biomass concentration and productivity reached $6.65 \mathrm{~g} / \mathrm{L}$ and $545 \mathrm{mg} / \mathrm{L} / \mathrm{d}$, and the synchronous lipid content and productivity reached $54.38 \%$ and $296.39 \mathrm{mg} / \mathrm{L} / \mathrm{d}$. Hypersalinity significantly promoted lipid contents at the cost of biomass and resulted in an increase of cell size but loss of spines of Golenkinia SDEC-16. The results shed new light on optimizing biomass and lipid productivity.
\end{abstract}

Keywords: Golenkinia SDEC-16; Biomass concentration; High lipid content; Culture conditions; Carotenoids

\section{Introduction}

Oleaginous microalgae for biomass and lipid production has attracted immense attention in recent years, owing to their rapid growth rates, high lipid contents, valuable bio-products, and eco-friendly effects [1-3]. The widely used strains for biomass and lipid studies are green microalgae and cyanobacteria including, Chlorella spp, Scenedesmus spp, Spirulina spp., and Chlamydomonas spp. (Supplementary Figure S1). From the perspective of microalgal output, the lipid content of $30 \%$ is quite common in most of the species. In addition, strains with higher lipid content tend to grow slower than low lipid content strains [4].

Recently, we discovered Golenkinia SDEC-16 with a large and spiny cell and easy self-sediment for harvest [5], exhibiting great potential in both biomass yield and lipid accumulation. However, the biomass concentration $(2.09 \mathrm{~g} / \mathrm{L})$ and lipid content $(30.43 \%)$ of Golenkinia SDEC-16 [5] are still lower than the reported values (e.g., $4.72 \mathrm{~g} / \mathrm{L}$ of biomass concentration and $71.45 \%$ of lipid content in Eustigmatos cf. polyphem) [6]. Thus, maximizing the production of both biomass and lipid remains a contemporary challenge [7]. Therefore, the motivation of this study was to find a strategy to maximize both biomass yield and lipid accumulation. 
Additionally, studies around the Golenkinia sp. under different culture conditions are rare in comparison to the widely used strains. To our knowledge, the topics are concentrated on synthesis of chlorophyll [8], nutrition utilization under heterotrophic or autotrophic [9-11], physiology and ultrastructure [12,13], phylogenetic analysis [14-16], feedstock for target organic matters synthesis [17], hydrolysis of cells for carbohydrate extraction $[18,19]$, biomass for bioenergy and wastewater treatment $[5,20]$, etc. So, it is necessary to test the effects of culture conditions on Golenkinia SDEC-16.

Mounting evidence over the past decade shows that biomass and lipids are mostly influenced by light, nutrient utilization, and salinity (see Supplementary Figure S2). Generally, microalga proliferates rapidly as the increase in light intensity but stops growing when the light intensity is beyond light saturation [1]. In addition, the light intensity can change bio-composition and affect the production of starch or lipid. For example, higher productivity of lipid and starch was attained under high light intensity $\left(600 \mu \mathrm{mol}\right.$ photons $\left.\mathrm{m}^{-2} \mathrm{~s}^{-1}\right)$ [21].

Nitrogen is a crucial nutrient to support microalgal growth but constrains lipid synthesis at a high concentration [4], thus balancing nitrogen uptake is vital in its commercial and sustainability success [22]. For instance, Eustigmatos cf. polyphem exhibited a hyper-accumulation of lipid (72.01\% of dry weight) when supplied with $1 \mathrm{mM}$ initial nitrogen [6]. When nitrogen is deficient, microalgal cells remobilize the carbon stream to enrich more lipids and starch [23]. Unfortunately, lipid hyper-accumulation by nitrogen deficiency is at the cost of microalgae growth, so the strategy failed to maximize the overall lipid productivity [24]. For instance, the biomass concentration of Eustigmatos cf. polyphem was only $4.72 \mathrm{~g} / \mathrm{L}$ at $1 \mathrm{mM}$ initial nitrogen concentration, which is inferior to $7.80 \mathrm{~g} / \mathrm{L}$ at $18 \mathrm{mM}$ nitrogen [6].

Salinity plays a positive role in lipid synthesis [25]. As an example, an increment of initial $\mathrm{NaCl}$ concentration from 0.5 to $1.0 \mathrm{M}$ in Dunaliella resulted in higher intracellular lipid content from $60 \%$ to $67 \%$ [26]. However, microalgae would loss biomass if the salinity remained at extremely high levels [27]. Importantly, the adaptability to change culture conditions is dependent on specific species. Therefore, it is necessary to determine appropriate initial nitrogen and $\mathrm{NaCl}$ concentrations to maintain the balance between the biomass concentration and lipid content.

The purpose of this study was to propose an effective strategy in achieving high biomass and lipid productivity in Golenkinia SDEC-16. We carried out heuristic optimizations of light intensities, initial nitrogen, and $\mathrm{NaCl}$ concentrations, and the results show that biomass and lipid content in Golenkinia SDEC-16 are among the highest among green microalgae. The insights gained in this study open a new avenue in optimizing culture conditions of Golenkinia SDEC-16 for renewable energy.

\section{Method and Materials}

\subsection{Experimental Design}

\subsubsection{Microalgal Strains}

The microalga strain used in this study was Golenkinia SDEC-16 (GeneBank accession number: KT180320) isolated from a local lake in Jinan, Shandong Province, China. Previous cultivations of Golenkinia SDEC-16 were performed in the photo-bioreactors with BG11 liquid medium at $25 \pm 2{ }^{\circ} \mathrm{C}$ to attain healthy cells for further study.

\subsubsection{Light Intensity}

The following experiments were conducted in the Erlenmeyer flasks containing $500 \mathrm{~mL}$ BG11 medium with aeration of $1.0 \mathrm{~L} / \mathrm{min}$ under a photoperiod $\left(24: 0 \mathrm{~h}\right.$ of light: dark period) at $25 \pm 2{ }^{\circ} \mathrm{C}$ for 12 days, and all of the experiments were carried out in triplicate. The light was provided by a row of LEDs that were horizontally fixed on the shelves on one side. Four of the Erlenmeyer flasks received continuous light intensities $(10,000,15,000,20,000$, and 25,000 lux), measured by a photometer by changing the positions toward the light source, which was considered to be the light intensity value used in the experiments. 


\subsubsection{Initial Nitrogen Concentration}

In this study, the basal medium was BG11, which contained sodium nitrate as the nitrogen source. Two initial $\mathrm{NaNO}_{3}$ concentrations ( $1 \mathrm{mM}$ and $9 \mathrm{mM}$ ) were exposed to the 10,000 lux and 25,000 lux, respectively. The experiments with aeration of $1.0 \mathrm{~L} / \mathrm{min}$ were carried out in the Erlenmeyer flasks containing $500 \mathrm{~mL}$ modified BG11 medium, under a photoperiod (24: $0 \mathrm{~h}$ of light: dark period) at $25 \pm 2{ }^{\circ} \mathrm{C}$ for twelve days, and all of the experiments are carried out in triplicate.

\subsubsection{Initial Sodium Chloride Concentration}

In this study, the basal medium was optimized BG11 (initial nitrogen concentration of $9 \mathrm{mM}$ ). The initial sodium chloride concentrations were 20,160,320, and $640 \mathrm{mM}$ with aeration of $1.0 \mathrm{~L} / \mathrm{min}$ upon exposure to the 25,000 lux light intensity. The experiments were carried out in Erlenmeyer flasks containing $500 \mathrm{~mL}$ modified BG11 medium with $\mathrm{NaCl}$, under a photoperiod (24: $0 \mathrm{~h}$ of light: dark period) at $25 \pm 2{ }^{\circ} \mathrm{C}$ for 12 days, and all of the experiments were carried out in triplicate.

\subsection{Microalgal Analyses}

\subsubsection{Biomass Measurements}

The microalgal growth was determined by weighing the constantly dry biomass. A $5 \mathrm{~mL}$ volume of microalgal solution was filtered by a pre-dried and pre-weighed $0.45 \mu \mathrm{m}$ cellulose nitrate membrane to remove the supernatant. The filtered microalgae were transferred to a clean and weighed aluminum foil dish, which was then dried to become constant mass in a thermostatically controlled oven at $60^{\circ} \mathrm{C}$. The biomass productivity, $P_{\mathrm{b}}$ (mg L/day) was calculated according to Equation (1),

$$
P_{\mathrm{b}}=\frac{X_{\mathrm{m}}-X_{0}}{(\Delta t) V}
$$

where $X_{\mathrm{m}}$ and $X_{0}$ are the respective concentrations of biomass $(\mathrm{g} / \mathrm{L})$ at the end and beginning of a batch run, $V$ is the volume of one sample, and $\Delta t$ is the duration of the run.

\subsubsection{Lipid Content}

The lipid content was measured by solvent extraction and gravimetry [28]. The harvested microalgae were freeze-dried and then ground to an approximately uniform powder for lipid extraction. About $0.1 \mathrm{~g}$ of dry biomass powder was mixed with $10 \mathrm{~mL}$ of chloroform-methanol solution $(2: 1, \mathrm{v} / \mathrm{v})$ in a centrifuge tube. The mixture was treated by ultrasonication (Ultrasonic Cell Crusher, SCIENTZ-IID, China) for $10 \mathrm{~min}$ and subsequently centrifuged at $2000 \mathrm{~g}$ for $10 \mathrm{~min}$ at $4{ }^{\circ} \mathrm{C}$. The supernatant was moved to a clean and dry $60 \mathrm{~mL}$ separatory funnel. The entire extraction process was repeated twice. After the extraction, $\mathrm{NaCl}$ solution $(0.9 \%)$ of one fifth the volume of the supernatant was added into the separatory funnel. The mixture was shaken well for $1 \mathrm{~min}$ and then kept still for $15 \mathrm{~min}$ to stratify. The volume of the lower-phase solution was measured, and $5 \mathrm{~mL}$ of the lower-phase solution was then transferred to a clean $10 \mathrm{~mL}$ glass tube. The solvent in the $5 \mathrm{~mL}$ sample then evaporated under a nitrogen stream. The tube containing lipid was dried in an oven at $60^{\circ} \mathrm{C}$ to attain a constant weight. The lipid content $(L C)$ was expressed as a fraction of the dry weight and calculated based on the formula

$$
L C=\left(m_{2}-m_{1}\right) \times V /\left(5 \times m_{0}\right)
$$

where $m_{0}(\mathrm{~g})$ is the weight of algae powder, $m_{1}(\mathrm{~g})$ and $m_{2}(\mathrm{~g})$ are the weights of the empty glass tube and the tube containing dried lipid, respectively, and $V(\mathrm{~mL})$ is the volume of the lower phase.

Lipid productivity $(L P, \mathrm{~g} / \mathrm{L} / \mathrm{d})$ was determined according to the following formula:

$$
L P=P_{\mathrm{b}} \times L C / \Delta t
$$


where $L C(\%)$ is the corresponding lipid content, and $\Delta t$ (days) is the total algal cultivation time.

\subsubsection{Microalgal Cell Size Measurement}

Lengths of cells' radiuses and outer spines at the end of the experimental groups are recorded by an inverted fluorescence microscope (Ti-s, Nikon, Japan). Statistical analyses of the algal cells were computed with NIS-Elements D 4.20.00 software (Nikon, Japan).

\subsubsection{Pigments Measurements}

Pigments contents measurement procedures were as follows. First, a $2 \mathrm{~mL}$ culture was centrifuged at $9000 \mathrm{~g}$ for $10 \mathrm{~min}$ to discard the supernatant. The pellet was mixed with methanol and broken via grinding. Then, the mixture was incubated in darkness for $24 \mathrm{~h}$ at $45^{\circ} \mathrm{C}$. Subsequently, the solution was centrifuged at $9000 \mathrm{~g}$ for $10 \mathrm{~min}$. The absorbance of the supernatant was measured at wavelengths of $470 \mathrm{~nm}, 652.4 \mathrm{~nm}, 665.2 \mathrm{~nm}$, and $750 \mathrm{~nm}$ on a UV-visible spectrophotometer (ZDS-10, Shanghai Cany Precision Instrument, China). Concentration was calculated according to following the formulas [29]:

$$
\begin{gathered}
\text { Chlorophyll a }(\mu \mathrm{g} / \mathrm{mL})=16.72 A_{665.2}-9.16 A_{652.4} \\
\text { Chlorophyll b }(\mu \mathrm{g} / \mathrm{mL})=34.09 A_{652.4}-15.28 A_{665.2} \\
\text { Carotenoids }(\mu \mathrm{g} / \mathrm{mL})=\left(1000 A_{470}-1.63 c h l_{\mathrm{a}}-104.9 c h l_{\mathrm{b}}\right) / 221
\end{gathered}
$$

Absorbances at 470, 652.4, and $665.2 \mathrm{~nm}$ were corrected for turbidity by subtracting absorbance at $750 \mathrm{~nm}$.

\subsection{Nutrients Measurements}

Filtered samples were used to test total organic carbon concentration by TOC analyzer (TOC-L CPN CN200, Shimadzu, Japan). The total nitrogen (TN), ammonium, and total phosphorus (TP) were determined according to the Chinese state standard testing methods [30].

\subsection{Experiment of Water Replenishment}

The effects of water loss on microalgal biomass production were evaluated under the optimized culture conditions. The settings were as follows: the control group was cultivated without any additional operations, and the other one was added distilled water to ensure identical to the initial volume every day. The biomass concentrations and real production were recorded.

\section{Results}

\subsection{Effects of Culture Conditions on Biomass Concentration}

Figure 1 shows the characteristics of the biomass concentrations and lipid contents in Golenkinia SDEC-16 under light intensities, initial nitrogen, and $\mathrm{NaCl}$ concentrations. The maximal biomass concentration was $5.27 \mathrm{~g} / \mathrm{L}$ under the light intensity of $25,000 \mathrm{lux}$, followed by $5.18,4.98$, and $4.88 \mathrm{~g} / \mathrm{L}$ under 20,000, 15,000, and 10,000 lux, respectively.

Reduced initial nitrogen concentration significantly affected biomass yield. At a $1 \mathrm{mM}$ initial nitrogen concentration, the biomass concentrations decreased to $3.5 \mathrm{~g} / \mathrm{L}$ and $3.8 \mathrm{~g} / \mathrm{L}$ under light intensities of 10,000 lux and 25,000 lux, respectively, which were lower than those in the BG11 medium under the same light intensities. When the initial nitrogen concentration was $9 \mathrm{mM}$, the biomass concentrations were $4.45 \mathrm{~g} / \mathrm{L}$ and $5.28 \mathrm{~g} / \mathrm{L}$, respectively, upon exposure to 10,000 lux and 25,000 lux, which were nearly identical to those in BG11 upon exposure to the same light intensities. The results illustrated that the over-reduction of initial nitrogen concentration exerted an adverse effect on microalgal growth. 


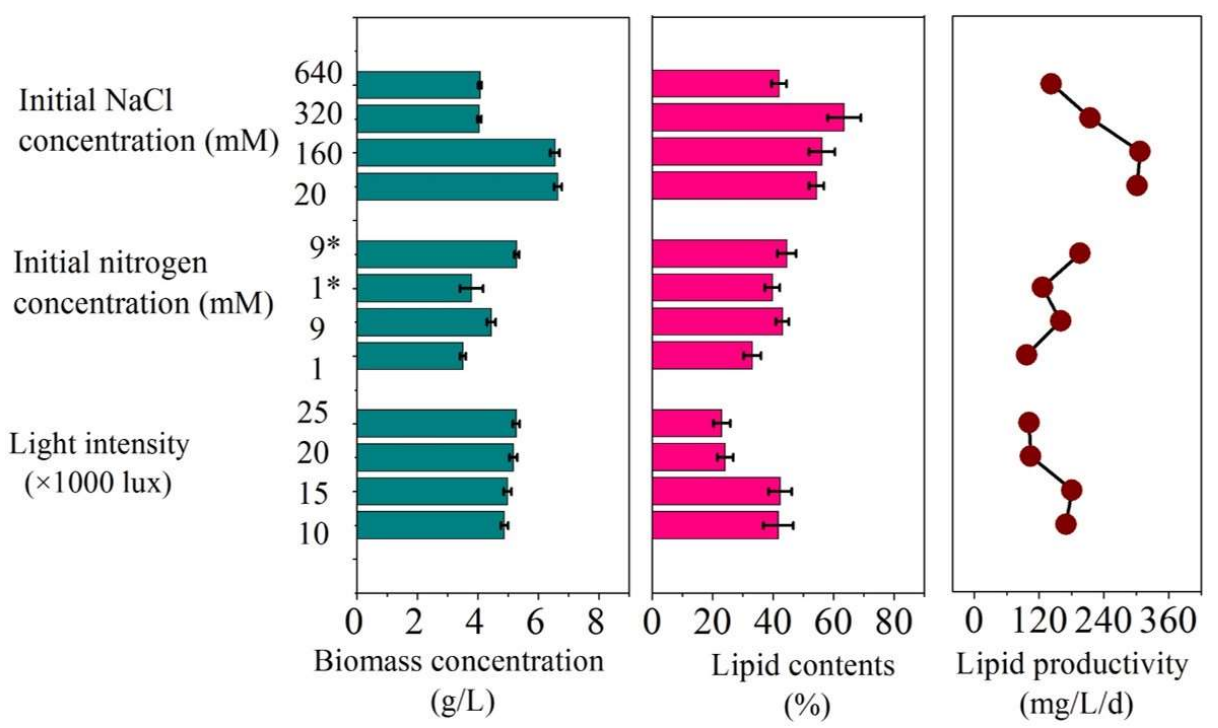

Figure 1. Biomass concentrations, lipid contents, and lipid productivities of Golenkinia SDEC-16 were exposed to different culture conditions. In the initial nitrogen concentration group, 1 and 9 represent $1 \mathrm{mM}$ and $9 \mathrm{mM}$ initial nitrogen concentrations under the 10,000 lux; $1^{*}$ and $9^{*}$ represent $1 \mathrm{mM}$ and $9 \mathrm{mM}$ initial nitrogen concentrations under the 25,000 lux.

The biomass concentration decreased in the medium with the increase in initial $\mathrm{NaCl}$ concentration, and a maximum yield was obtained $(6.65 \mathrm{~g} / \mathrm{L})$ at a level of $20 \mathrm{mM} \mathrm{NaCl}$. This biomass yield $(6.65 \mathrm{~g} / \mathrm{L})$ was the highest in comparison to other experimental groups, which was about 1.3 times as much as the maximal biomass yield $(5.28 \mathrm{~g} / \mathrm{L})$ in the medium without $\mathrm{NaCl}$.

\subsection{Effects of Culture Conditions on Lipid Accumulation}

As shown in Figure 1, a significant change in lipid contents was observed under different light intensities. Under 10,000 lux and 15,000 lux, the lipid contents were $41.77 \%$ and $42.34 \%$, which were appreciably higher than those under 20,000 (24.19\%) and 25,000 (23.07\%) lux. Given the conflict between biomass concentration and lipid accumulation, a strategy of reduced initial nitrogen concentration was introduced, and lipid synthesis was enhanced. Specifically, under 10,000 lux, the lipid content reduced to $33.17 \%$, which is lower than that in the BG11 medium, when the initial nitrogen concentration was $1 \mathrm{mM}$. However, the lipid content (43.16\% of dry biomass) at the $9 \mathrm{mM}$ initial nitrogen concentration was similar to that in BG11. In contrast, under 25,000 lux, the lipid contents reached $39.82 \%$ and $44.59 \%$ of dry biomass at $1 \mathrm{mM}$ and $9 \mathrm{mM}$ of the initial nitrogen concentrations, respectively, which were 1.65 and 1.93 times higher than those obtained in BG11 upon exposure to the same light intensities. Hence, the $9 \mathrm{mM}$ of initial nitrogen concentration can compensate for the low lipid content and exert no effects on biomass concentration under the 25,000 lux.

To further enhance lipid accumulation, $\mathrm{NaCl}$ was introduced. An increase in initial $\mathrm{NaCl}$ concentrations from $20 \mathrm{mM}$ to $320 \mathrm{mM}$ resulted in the enhancement of lipid content up to $63.51 \%$, but lipid content decreased at $640 \mathrm{mM} \mathrm{NaCl}$. Thus, the optimized $\mathrm{NaCl}$ concentration is $320 \mathrm{mM}$.

Lipid productivity can reflect both biomass concentration and lipid accumulation, and it is an essential indicator for biofuel production. It is worth noting that higher lipid productivities (166.01 and $176.93 \mathrm{mg} / \mathrm{L} / \mathrm{d})$ were attained under low light intensities $(10,000$ and 15,000 lux), which illustrated that lipid production needs to consider both biomass concentrations and lipid contents. Regarding the nitrogen group, the highest lipid productivity, $189.91 \mathrm{mg} / \mathrm{L} / \mathrm{d}$, was attained at a $9 \mathrm{mM}$ initial nitrogen concentration under 25,000 lux light intensity. Similar to the case of lipid content, introduced $\mathrm{NaCl}$ facilitates lipid productivity, and the highest value was $296.39 \mathrm{mg} / \mathrm{L} / \mathrm{d}$ in the medium supplemented with $\mathrm{NaCl}$ at $20 \mathrm{mM}$, which was approximately 1.5 and 1.4 times higher than that at 0 and $320 \mathrm{mM}$ of initial $\mathrm{NaCl}$ concentrations. Taken together, the optimal culture conditions for 
synchronous accumulation of biomass and lipid are as follows, 25,000 lux, $9 \mathrm{mM}$ initial nitrogen concentration, and $20 \mathrm{mM}$ initial $\mathrm{NaCl}$ concentration.

\subsection{Effects of Culture Conditions on Microalgal Morphology}

Cell size plays a pivotal role in maintenance and culture productivity [31]. The holotype of Golenkinia sp presents that the cells possessed 5-10 $\mu \mathrm{m}$ of radius, and cells are irregularly arranged numerous spines [32]. As depicted in Figure 2, cell radiuses and spine lengths of Golenkinia SDEC-16 were substantially affected by the ambient change. The average radiuses in the light group were 7.61 , $8.00,8.47$, and $8.13 \mu \mathrm{m}$, corresponding to the $10,000,15,000,20,000$, and 25,000 lux. Regarding initial nitrogen concentrations, upon exposure to the 10,000 lux and 25,000 lux light intensity, the average radiuses were $8.01 \mu \mathrm{m}$ and $7.93 \mu \mathrm{m}$ at $9 \mathrm{mM}$, and were $8.95 \mu \mathrm{m}$ and $8.70 \mu \mathrm{m}$ at $1 \mathrm{mM}$, respectively. The cell radius was enlarged as the salinity was increased, while reduced at higher concentration, with the highest values (14.34 $\mu \mathrm{m}$ and $18.50 \mu \mathrm{m}$ for average and maximum, respectively) occurring at $320 \mathrm{mM}$ initial $\mathrm{NaCl}$ concentration.
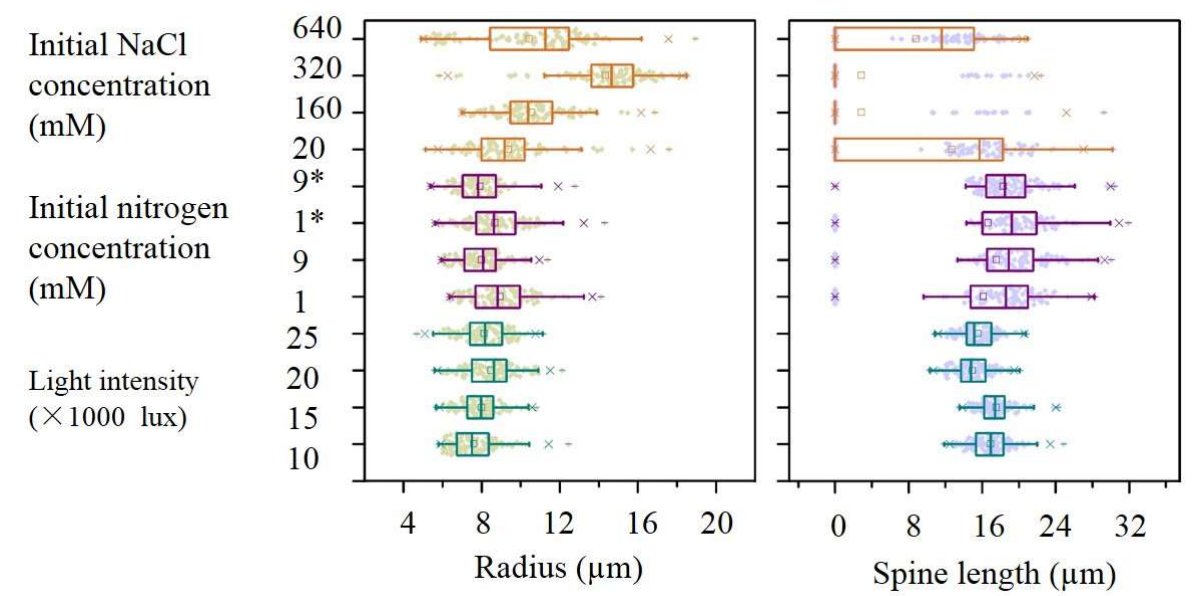

Figure 2. Cell radiuses and spine lengths of Golenkinia SDEC-16 were exposed to different culture conditions. In the initial nitrogen concentration group, 1 and 9 represent $1 \mathrm{mM}$ and $9 \mathrm{mM}$ initial nitrogen concentrations under the $10,000 \mathrm{lux} ; 1^{*}$ and $9^{*}$ represent $1 \mathrm{mM}$ and $9 \mathrm{mM}$ initial nitrogen concentrations under the 25,000 lux.

In terms of spines, the spine lengths of Golenkinia SDEC-16 at reduced initial nitrogen concentrations were all longer than those in the light intensity groups. Conversely, the increasing salinity is the main factor shortening the spine lengths. Cultivations at $160 \mathrm{mM}$ and $320 \mathrm{mM}$ initial NaCl make the most of algal cells discard their spines, resulting in zero of the median value. There was a proportion of cells without spines, although the higher median values were $15.72 \mu \mathrm{m}$ and $11.59 \mu \mathrm{m}$ at $20 \mathrm{mM}$ and $640 \mathrm{mM}$ initial sodium chloride concentrations.

\subsection{Effects of Culture Conditions on Pigments Production}

Green microalgae are rich in pigments, especially chlorophyll, which is a valuable byproduct for improving human health. Changes in chlorophyll were also measured in the present work to reveal the effect of change in culture conditions (Figure 3). The chlorophyll-a content was strongly affected by light intensities. Initially, the chlorophyll-a increased upon exposure to 10,000 lux compared with 80,000 lux, with the highest value $(17.83 \mathrm{mg} / \mathrm{g})$, and then decreased gradually as light intensified. The chlorophyll-a contents decreased with deceasing initial nitrogen concentration in comparison to the BG11. Besides, the increase in salinity retarded chlorophyll-a accumulation. 


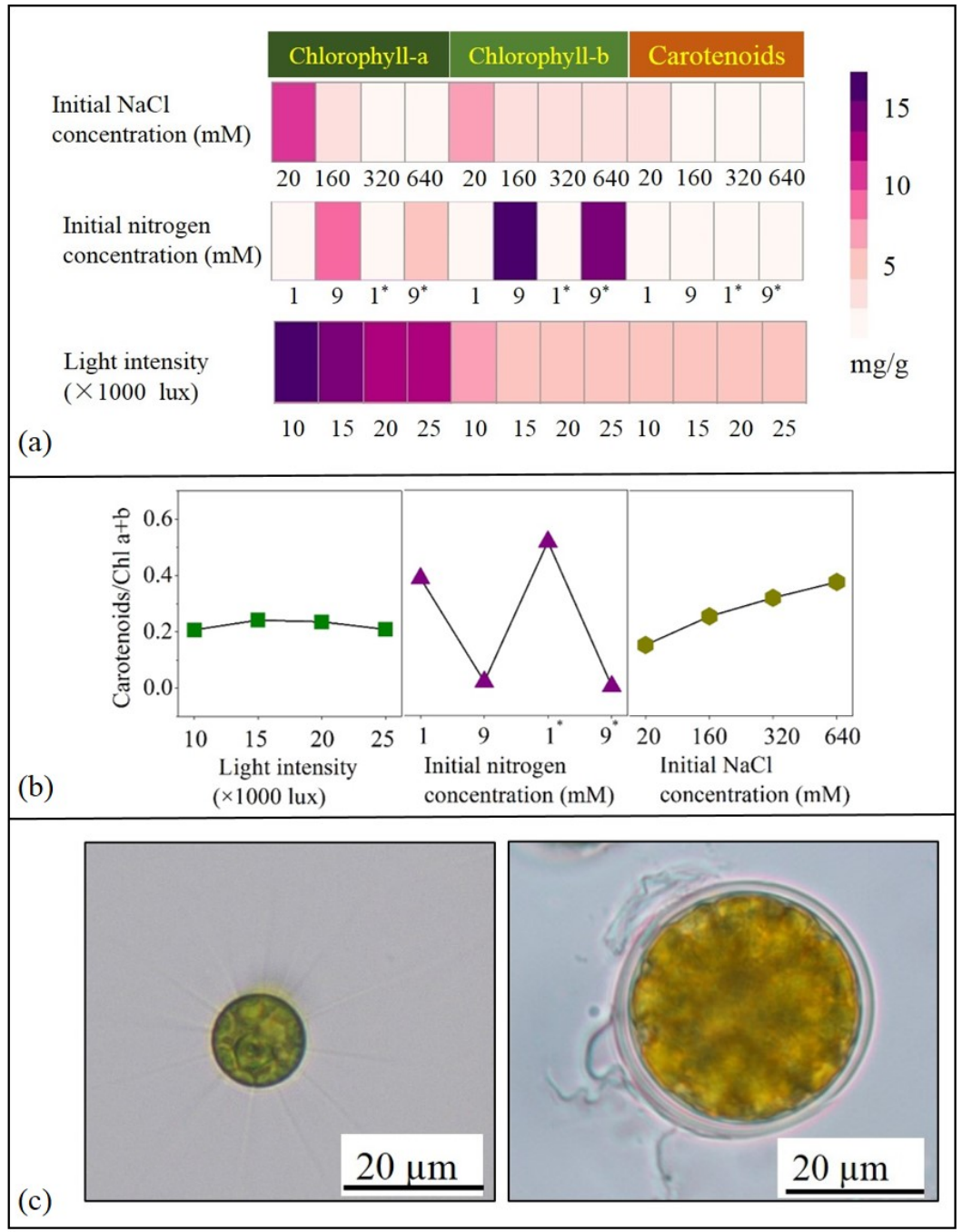

Figure 3. Chlorophyll contents of Golenkinia SDEC-16 were exposed to different culture conditions: (a) chlorophyll-a, chlorophyll-b, and carotenoids contents; (b) the ratio between carotenoids and chlorophyll a and b; (c) photos display Golenkinia SDEC-16 in BG11 and enlarged cells under salinity stress conditions. In the initial nitrogen concentration group, 1 and 9 represent $1 \mathrm{mM}$ and $9 \mathrm{mM}$ initial nitrogen concentrations under the 10,000 lux; $1^{*}$ and 9* represent $1 \mathrm{mM}$ and $9 \mathrm{mM}$ initial nitrogen concentrations under the 25,000 lux.

The chlorophyll-b was weakly affected by changes of light intensities, and salinity, except for initial nitrogen concentrations. The contents for chlorophyll-b were up to $17.13 \mathrm{mg} / \mathrm{g}$ and $13.75 \mathrm{mg} / \mathrm{g}$ at $9 \mathrm{mM}$ initial nitrogen concentration under the 10,000 lux and 25,000 light intensities, respectively. The lower values of chlorophyll-b were $1.33 \mathrm{mg} / \mathrm{g}$ and $0.91 \mathrm{mg} / \mathrm{g}$ in media, which were provided by $1 \mathrm{mM}$ initial nitrogen concentration under the same light intensities. High values of carotenoids were attained under light intensities of 10,000 lux and 15,000 lux, corresponding to $4.96 \mathrm{mg} / \mathrm{g}$ and $4.97 \mathrm{mg} / \mathrm{g}$. The nitrogen deficiency and the hypersalinity played a negative role in carotenoids accumulation.

\subsection{Effects of Culture Conditions on Nutrient Utilisations}

Nutrients are central to the metabolisms of microalgae. Figure 4 quantitatively depicts the nutrient variation in algae. The total organic carbon (TOC) concentrations were low at begin, owing to autotrophic mode, and then increased in all of the treatment groups in the end since natural complexes, such as exopolysaccharide and glycoproteins, exerted from microalgae or dead cells $[33,34]$. The peaks of TOC concentrations were $896.07 \mathrm{mg} / \mathrm{L}$ under the light intensity of 20,000 lux and $531.21 \mathrm{mg} / \mathrm{L}$ at 
$9 \mathrm{mM}$ initial nitrogen concentration. A downtrend was observed with an increase in initial $\mathrm{NaCl}$ concentrations, and the highest value for TOC concentration was $338.86 \mathrm{mg} / \mathrm{L}$ in the media with initial $\mathrm{NaCl}$ at $20 \mathrm{mM}$.

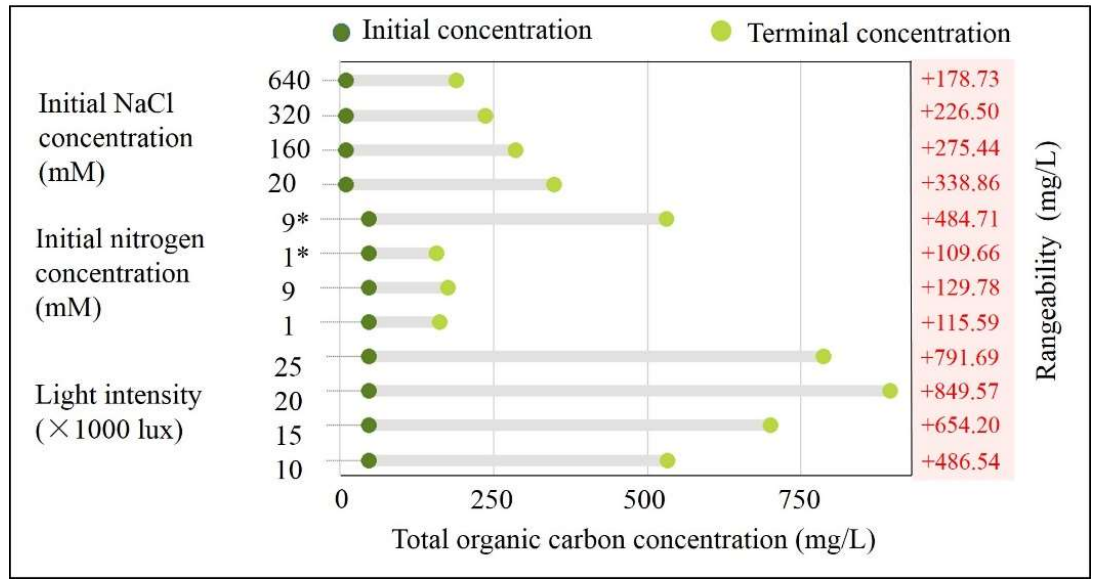

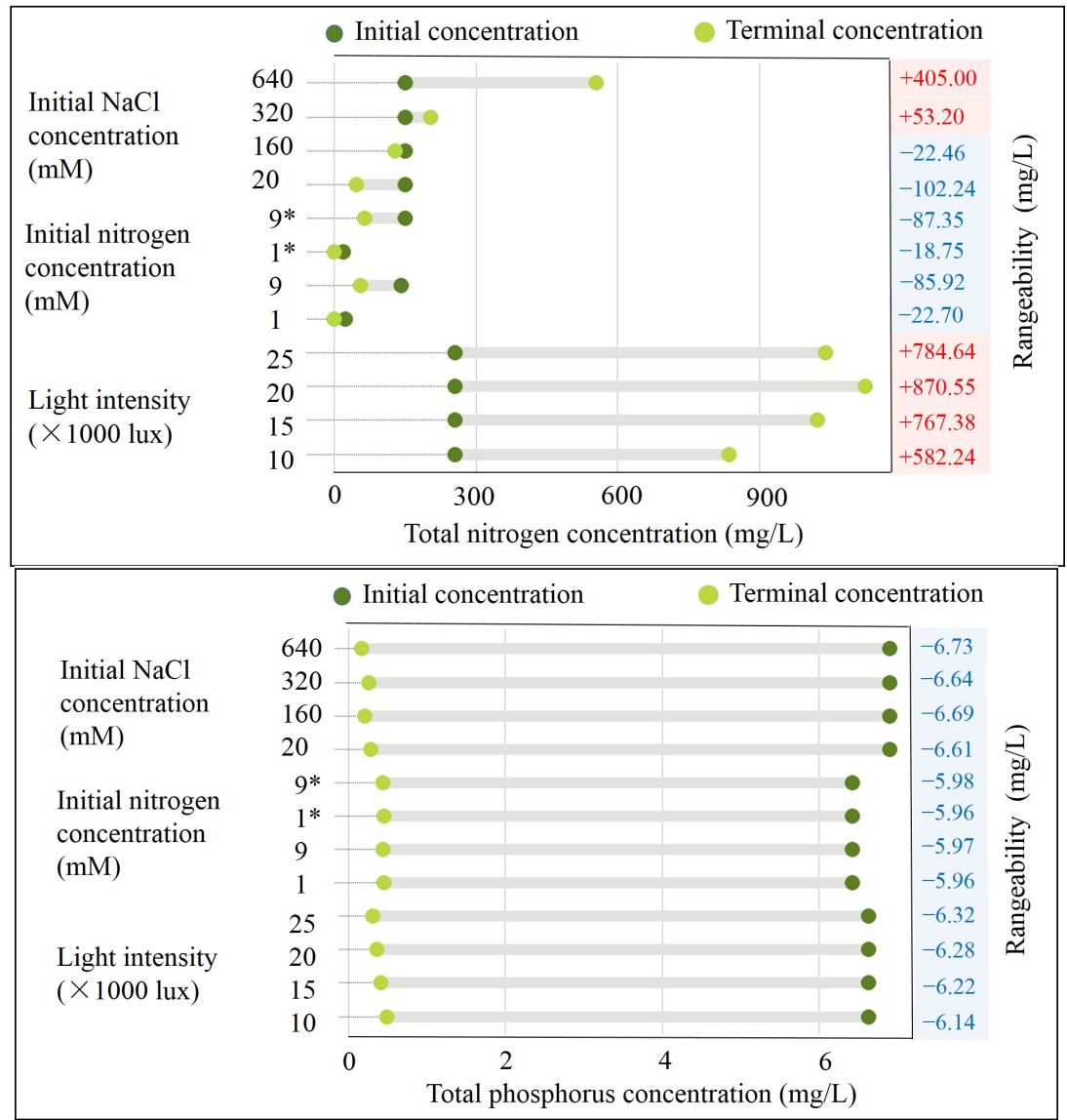

Figure 4. The residue concentrations of total organic carbon, total nitrogen, and total phosphorus were exposed to different culture conditions. In the initial nitrogen concentration group, 1 and 9 represent $1 \mathrm{mM}$ and $9 \mathrm{mM}$ initial nitrogen concentrations under the $10,000 \mathrm{lux}$, and $1^{*}$ and $9^{*}$ represent $1 \mathrm{mM}$ and $9 \mathrm{mM}$ initial nitrogen concentrations under the 25,000 lux.

The maximal residue of total nitrogen concentrations was $1039.01 \mathrm{mg} / \mathrm{L}$ under 20,000 lux, followed by $1124.93,1021.76,836.62 \mathrm{mg} / \mathrm{L}$ under 20,000, 15,000, and 10,000 lux. The residue total nitrogen 
concentration decreased when the initial nitrogen concentration reduced. The residue total nitrogen concentrations were $56.14 \mathrm{mg} / \mathrm{L}$ and $63.33 \mathrm{mg} / \mathrm{L}$ at $9 \mathrm{mM}$ initial nitrogen concentrations under light intensities of 10,000 lux and 25,000 lux, respectively. Under the same light intensities, the total nitrogen was utterly taken up at $1 \mathrm{mM}$ of initial nitrogen concentration. The residue total nitrogen concentration increased gradually with higher initial $\mathrm{NaCl}$ concentrations, the lowest residue of concentration of which was $47.51 \mathrm{mg} / \mathrm{L}$ in a media that supplemented with $20 \mathrm{mM}$ initial $\mathrm{NaCl}$. Phosphorus is also vital for microalgal metabolism. Phosphorus participates into generating ATP through phosphorylation along with adenosine diphosphate (ADP) [4]. In the present work, total phosphorus was consumed entirely in all the experimental groups.

\subsection{The Relationship between Microalgal Indicators}

Correlations among microalgal indicators of Golenkinia SDEC-16 are depicted in Figure 5. The biomass concentrations exhibited no statistically significant associations with other indicators. Lipid content significantly shows a positive correlation with the cells' radius and significantly negative relationships with spine length and the residues of TOC concentration and total nitrogen concentration. Chlorophyll-a shows a negative association with radiuses and significantly positive correlations with carotenoids, the residue of TOC, and the total nitrogen. Carotenoids contents also exhibited a positive relationship with the residue of TOC and nitrogen concentration. A statistically significant negative correlation existed between radius and spine, and a positive correlation existed between the residue of TOC and nitrogen concentrations.

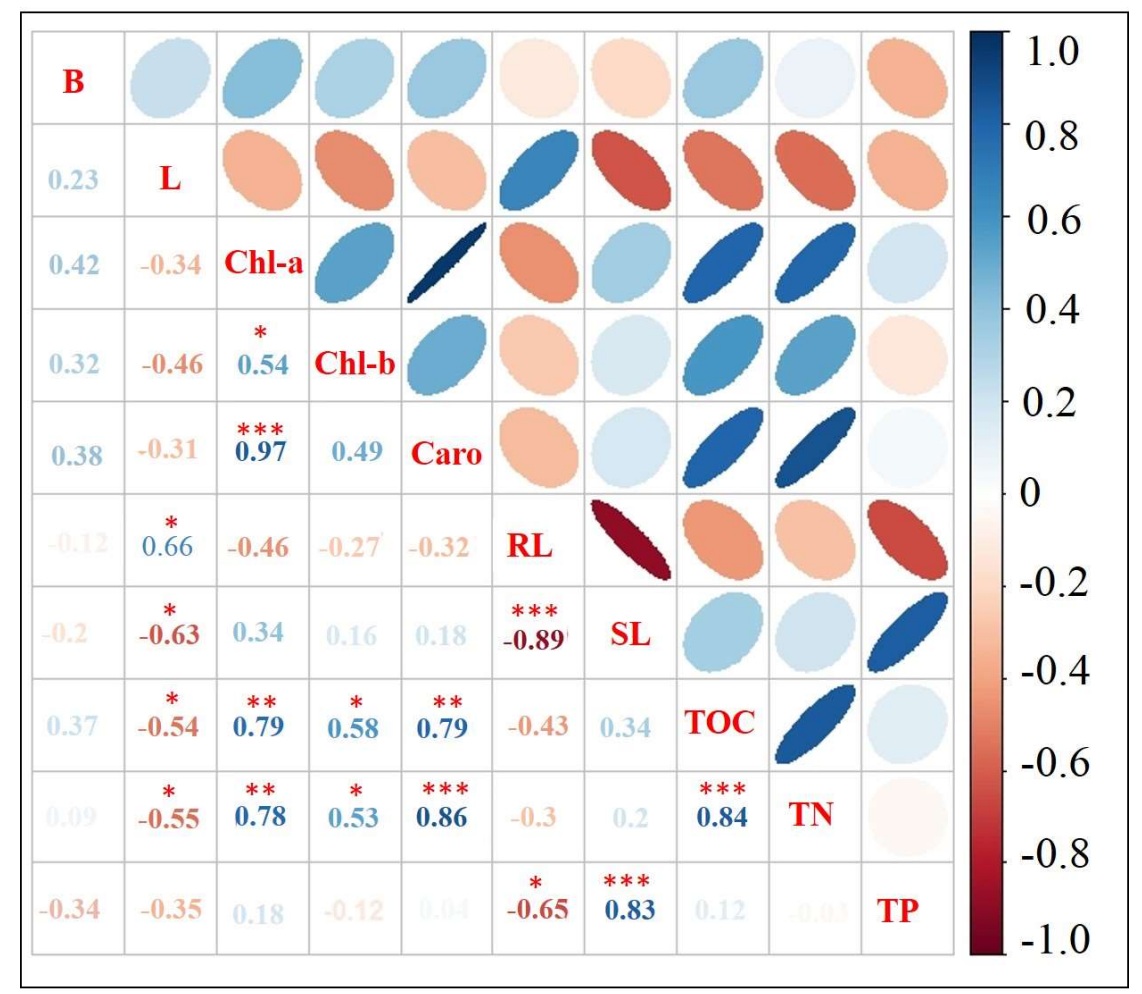

Figure 5. Correlation between microalgal indicators. Biomass (B) represents the final microalgal biomass concentration. Lipid (L) represents the final microalgal lipid contents. Chlorophyll-a (Chl-a) represents chlorophyll-a contents. Chlorophyll-b (Chl-b) represents chlorophyll-b contents. Caotenoid (Caro) represents carotenoid contents. Radius lengths (RL) represents the radius of cells. Spine lengths (SL) represents the microalgal spine lengths. Total organic carbon (TOC) represents the final total organic carbon concentration. Total phosphorus (TP) represents the final total phosphorus concentration. Total nitrogen (TN) represents the final total nitrogen concentration. 


\section{Discussion}

Changes in light intensity remarkably affected the biomass concentration and lipid content of Golenkinia SDEC-16. It is well acknowledged that microalgae grew rapidly with an increase in light intensity, but it stopped growing when exposed to strong light intensity. The excess light causes photooxidation to PSII components, which results in photoinhibition. Photoinhibition damaged essential proteins required for the electron transfer in photosynthesis, which resulted in lowering biomass productivity [35]. Nevertheless, the densest biomass concentration was attained under the 25,000 lux at the end of the culture. It might be ascribed to light counteraction by microalgal self-shading against damage by intense light when the cell density turned dense.

Lipid content is enhanced by increasing light intensity through activating critical enzymes in the synthesis process of fatty acid [36]. Previous work showed lipid content for Golenkinia SDEC-16 was $37.8 \%$ in BG11 under the 5,000 lux on day eight [5]. In the present work, the lipid content was promoted under the 10,000 lux and 15,000 lux but sharply dropped under the 20,000 lux and 25,000 lux, respectively, stating that there is a peak of light intensity that can benefit lipid synthesis. Similarly, Chlorella vulgaris was found to obtain the maximal lipid content under the peak $(560 \mu \mathrm{mol}$ $\mathrm{m}^{-2} \mathrm{~s}^{-1}$ ) of given light intensities [37]. Given that distinct behaviors of biomass concentration and lipid accumulation under 10,000 lux and 25,000 lux, strategies that reduce initial nitrogen concentrations were subsequently evaluated to make compensation to low lipid content.

Nitrogen is one of the essential nutrients for microalgae, and limitation or redundancy of nitrogen supply can affect the biomass concentration and change the biochemical composition. Microalgae utilize nitrate by nitrate enzymes and transferred nitrate as ammonium to participate in metabolism [4]. According to Figures 1 and 4, the results indicate that the $1 \mathrm{mM}$ initial nitrogen concentration is too insufficient to support the Golenkinia SDEC-16 growth and the $9 \mathrm{mM}$ initial nitrogen concentration can play an identical role to the BG11 in the growth of Golenkinia SDEC-16. Additionally, the $9 \mathrm{mM}$ initial nitrogen could be greatly consumed in comparison to the BG11, illustrating that the $9 \mathrm{mM}$ is the economical level in the application of microalgae cultivation.

As for lipid synthesis, the most commonly known is that nitrogen limitation effectively increased the lipid accumulation [38]. Generally, nitrogen limitation imposes changes upon the microalgae in three aspects. First, the cellular content of the thylakoid membrane is decreased. Second, acyl hydrolase is activated, and the phospholipid hydrolysis is stimulated. Third, the intracellular content of fatty acid acyl-CoA may be enhanced via those changes and be converted to triglyceride via activated diacylglycerol induced by nitrogen limitation. Therefore, nitrogen limitation could facilitate both lipid and TAG synthesis in microalgal cells [4]. The lipid content of green algae under the nitrogen deprivation could be multiplied up to two-to-three-fold [4]. Interestingly, both increases and decreases in the lipid contents have been reported in some microalgae, depending on the species $[4,6]$. For instance, the lipid contents of five Eustigmatophytes species significantly increased as the initial nitrogen concentration decreased from $18 \mathrm{mM}$ to $1 \mathrm{mM}$, except for Vacuoliviride sp., which exhibited an opposite trend [6]. In the present work, the results indicate that the reduction of initial nitrogen concentration under 25,000 lux can facilitate the lipid synthesis but exert little effects on lipid synthesis under 10,000 lux.

For the sake of further enhancement of lipid content, supplementation with $\mathrm{NaCl}$ was evaluated. Salinity stress affected microalgae in three types-(1) ionic stress broke the balance of ion homeostasis, (2) high salt-reduced osmotic potential and water uptake, and (3) generation of reactive oxygen species (ROS) caused oxidative stress [39]. ROS exerted adverse effects on cells and made microalgae responded by facilitating antioxidative enzymes. Moreover, salinity stress changed membrane composition by regulating ion transporters [40]. That is the reason that microalga cannot survive in a high salinity environment.

In accordance, media with hypersalinity retarded the biomass yield in the present work. Surprisingly, low initial salinity facilitated the biomass accumulation in comparison to previous experimental groups. We speculated that Golenkinia SDEC-16 took up more nutrients, as evidenced 
by the higher reduction of nitrogen concentration $(102.24 \mathrm{mg} / \mathrm{L})$ at $20 \mathrm{mM}$ initial $\mathrm{NaCl}$ concentration. The lipid content increased gradually with salinity, while the content decreased with the initial $640 \mathrm{mM}$ $\mathrm{NaCl}$. The results indicate the $640 \mathrm{mM} \mathrm{NaCl}$ gave rise to severe impairs to Golenkinia SDEC-16 with the observations of low biomass concentration and pigment contents. The lipid content sharply decreased, primarily because the hypersalinity could not support the microalgal metabolism by the destruction of the thylakoid membranes and the reduction in photosynthetic activity and electron transport efficiency [27]. Therefore, we suggested culture conditions aiming at the maximal output are as follows, light intensity (25,000 lux), initial nitrogen concentration ( $9 \mathrm{mM})$, and initial $\mathrm{NaCl}$ concentration $(20 \mathrm{mM})$.

In terms of pigments, algae have developed specialized mechanisms to regulate more carotenoids with the help of a non-photochemical process to dissipate excess light energy [35]. Carotenoids can quench triplet excited states of chlorophylls through non-photochemical quenching and help chlorophylls received energy [41]. It is reported that up-regulations of the transcripts of carotenogenic genes, like $P D S, B K T$, and $C H Y b$, upon exposure to intense light irradiations [41]. Salt stress is another accepted driving force to enhance carotenoids accumulation [32,41] by up-regulation of carotenogenic genes $B K T$ [41].

In the present study, the highest carotenoids were attained under the 10,000 lux and 15,000 lux, although the orange-reddish of the cells occurred upon exposure to salinity stress. It is explained by the high ratios of carotenoids and chlorophyll $a+b$ at high salinity (Figure $3 b, c)$. Moreover, hypersalinity decreased chlorophyll $a$, chlorophyll $b$, and carotenoids via damages of photosystem II reaction centre [42]. The highest value of carotenoids in this work is higher than that in Golenkinia sp. FAUBA-3 $(2.1 \mathrm{mg} / \mathrm{g})$ [32]. Compared with published studies, contents for carotenoid were reported to range from $0.3 \mathrm{mg} / \mathrm{g}$ to $6.6 \mathrm{mg} / \mathrm{g}$ among 22 separate microalgal species [42]. Carotenoid content in Golenkinia SDEC-16 is in a high middle position compared with reported strains [42] but far below the value reported for a Scenedesmus sp. (34.2 mg/g of total carotenoid) [43]. Further studies will be undertaken to enhance carotenoid productivity through optimization of other culturing conditions. Therefore, we suggested culturing conditions aiming at the carotenoids output are as follows: light intensity (10,000 lux) and BG11 media.

Regarding associations among the microalgal indicators in Figure 5, no statistically significant correlations with biomass concentration illustrated that the description of biomass concentration varying should be limited to culturing conditions. For instance, biomass concentration decreased with an increase in lipid contents under the condition of growth from $20 \mathrm{mM}$ to $320 \mathrm{mM}$ of initial $\mathrm{NaCl}$, which was consistent with the trend of conflict between biomass and lipid accumulation. However, both biomass concentration and lipid content in the media with $20 \mathrm{mM}$ initial sodium chloride increased in comparison to mediums without salt under the same light intensities, which is against the view of the conflict between biomass and lipid accumulation.

The morphology of a longer cell radius with a shorter spine and the hyper-accumulation of lipid content concurrently occurred upon exposure to the salt stress. The extended cell size caused by hypersalinity gave rise to difficulties for the outer cell wall to envelop the whole cell (see Supplementary Figure S4). A positive relationship between the high TOC and nitrogen concentration indicates that cells were broke so that parts of the natural complexes in cells were discarded into the medium (see Supplementary Figure S4). The abundant nutrient might create a mixotrophic mode, improving efficiency in photosynthesis, which explained the positive association between pigments and nutrients.

Aside from the promotion of microalgal growth under optimal culturing conditions, water loss is a crucial factor to lead to hyper biomass concentration. The present work compared experimental groups with or without water replenishment. As depicted in Supplementary Figure S3, the final biomass concentration without water replenishments is far beyond group without water replenishment, although the final biomass production is similar, indicating high biomass concentrations benefited from water loss. The promotion of biomass and lipid productivity was achieved without water 
replenishment, and the residue culture medium can reduce cost, owing to less volume liquid required for harvesting.

Retrospective to the present work as seen in Table 1, both the biomass concentration and lipid content in Golenkinia SDEC-16 are clearly enhanced by the optimized culture conditions in comparison to the same genus in the published work. The results indicate the effective efforts in improving the Golenkinia SDEC-16 production. Regarding the microalgae under the autotrophic mode, the maximal biomass concentration $(6.65 \mathrm{~g} / \mathrm{L})$ in Golenkinia SDEC-16 under the optimized culture conditions caught up with some top outputs, such as Chlorella vulgaris FACHB-31 (5.57 g/L) [37], Eutigmatos cf. polyphem $(4.72 \mathrm{~g} / \mathrm{L})$ [6]. In addition, the lipid content $(54.38 \%)$ in Golenkinia SDEC-16 under the optimal culture condition located in a high position in the reported lipid contents compared with the widely used strains, such as Chlorella sp, Scenedesmus sp., illustrating the promising potential for renewable energy.

Table 1. Comparison of the biomass concentrations and lipid contents in Golenkinia SDEC-16 with published results.

\begin{tabular}{|c|c|c|c|c|}
\hline Species & Main Strategy & $\begin{array}{c}\text { Biomass } \\
\text { Concentration }(g / L)\end{array}$ & $\begin{array}{l}\text { Lipid Content } \\
(\%)\end{array}$ & Reference \\
\hline Golenkinia SDEC-16 & High light intensity & $4.88-5.27$ & $23.07-42.34$ & This study \\
\hline Golenkinia SDEC-16 & $\begin{array}{l}\text { High light intensity; } \\
\text { Decrease in nitrogen } \\
\text { High light intensity; }\end{array}$ & $3.5-5.28$ & $33.17-44.59$ & This study \\
\hline Golenkinia SDEC-16 & $\begin{array}{l}\text { Decrease in nitrogen; } \\
\text { Salinity stress }\end{array}$ & $4.04-6.65$ & $41.98-63.51$ & This study \\
\hline Golenkinia SDEC-16 & No stress & 2.05 & 30.43 & [5] \\
\hline $\begin{array}{l}\text { Golenkinia sp. } \\
\text { FAUBA-3 }\end{array}$ & Salinity stress & 1.02 & 37.2 & [32] \\
\hline $\begin{array}{l}\text { Eustigmatos cf. } \\
\text { polyphem }\end{array}$ & Nitrogen deficiency & 4.72 & 72.01 & [6] \\
\hline Chlorella vulgaris & High light intensity & 2.8 & 53.57 & [21] \\
\hline $\begin{array}{l}\text { Chlorella kessleri } \\
\text { NIES-2159 }\end{array}$ & High light intensity & 5.6 & 21.43 & [21] \\
\hline $\begin{array}{l}\text { Scenedesmus } \\
\text { obliquus XJ002 }\end{array}$ & Salinity stress & 0.22 & 32.26 & [27] \\
\hline $\begin{array}{c}\text { Chlorella vulgaris } \\
\text { FACHB-31 }\end{array}$ & High light intensity & 5.57 & 41.66 & [37] \\
\hline Chlorella sp & No stress & 1.53 & 24.97 & [42] \\
\hline Scenedesmus bijugus & No stress & 1.57 & 24.24 & [42] \\
\hline
\end{tabular}

\section{Conclusions}

For the sake of hyper-accumulation of biomass and lipid, the best culturing parameters were 25,000 lux of light intensity, $9 \mathrm{mM}$ of initial nitrogen concentration, and $20 \mathrm{mM}$ of initial $\mathrm{NaCl}$ concentration. Under these conditions, the final biomass concentration reached $6.65 \mathrm{~g} / \mathrm{L}$, and the biomass productivity was $545 \mathrm{mg} / \mathrm{L} / \mathrm{d}$. At the same time, the lipid content was as much as $54.38 \%$ of biomass and lipid productivity achieved $296.39 \mathrm{mg} / \mathrm{L} / \mathrm{d}$. The highest carotenoid value was $4.96 \mathrm{mg} / \mathrm{g}$ under the 10,000 lux, which can bring additional values.

Supplementary Materials: The following are available online at http://www.mdpi.com/1996-1073/13/4/964/s1, Figure S1: The distribution of published articles related to used strains and topics, Figure S2: The distribution of published articles related to culture conditions and research objectives, Figure S3: The biomass concentration and production of Golenkinia SDEC-16 under the conditions of water replenishment or not, Figure S4: Photos of Golenkinia SDEC-16 under thr salty stress.

Author Contributions: Investigation, C.N.; writing-original draft, C.N.; Formal analysis, C.N., L.J.; writing-review and editing, L.J., Q.H., Z.Y. (Zhigang Yang), Z.Y. (Ze Yu), H.P.; Supervision. H.P. All authors have read and agreed to the published version of the manuscript.

Funding: This work is supported by the the Department of Science and Technology of Shandong Province (Key R\&D Program (International Cooperation)), grant number: 2019GHZ030.

Conflicts of Interest: The authors declare no conflict of interest. 


\section{References}

1. Chia, S.R.; Ong, H.C.; Chew, K.W.; Show, P.-L.; Phang, S.-M.; Ling, T.C.; Nagarajan, D.; Lee, D.-J.; Chang, J.-S. Sustainable approaches for algae utilisation in bioenergy production. Renew. Energy 2018, 129, 838-852. [CrossRef]

2. Wijffels, R.H.; Barbosa, M. An Outlook on Microalgal Biofuels. Science 2010, 329, 796-799. [CrossRef] [PubMed]

3. Alam, M.M.; Mumtaz, A.S.; Russell, M.; Grogger, M.; Veverka, D.; Hallenbeck, P. Isolation and Characterization of Microalgae from Diverse Pakistani Habitats: Exploring Third-Generation Biofuel Potential. Energies 2019, 12, 2660. [CrossRef]

4. Sajjadi, B.; Chen, W.-Y.; Raman, A.; Ibrahim, S. Microalgae lipid and biomass for biofuel production: A comprehensive review on lipid enhancement strategies and their effects on fatty acid composition. Renew. Sustain. Energy Rev. 2018, 97, 200-232. [CrossRef]

5. Nie, C.; Pei, H.; Jiang, L.; Cheng, J.; Han, F. Growth of large-cell and easily-sedimentation microalgae Golenkinia SDEC-16 for biofuel production and campus sewage treatment. Renew. Energy 2018, 122, 517-525. [CrossRef]

6. Wang, F.; Gao, B.; Huang, L.; Su, M.; Dai, C.; Zhang, C. Evaluation of oleaginous eustigmatophycean microalgae as potential biorefinery feedstock for the production of palmitoleic acid and biodiesel. Bioresour. Technol. 2018, 270, 30-37. [CrossRef]

7. Jin, H.; Zhang, H.; Zhou, Z.; Li, K.; Hou, G.; Xu, Q.; Chuai, W.; Zhang, C.; Han, D.; Hu, Q. Ultrahigh-cell-density heterotrophic cultivation of the unicellular green microalga Scenedesmus acuminatus and application of the cells to photoautotrophic culture enhance biomass and lipid production. Biotechnol. Bioeng. 2019, 117, 96-108. [CrossRef]

8. Ellis, R.; Spooner, T.; Yakulis, R. Regulation of Chlorophyll Synthesis in the Green Alga Golenkinia. Plant Physiol. 1975, 55, 791-795. [CrossRef]

9. Ellis, R.J. Control of sexuality in Golenkinia. Am. J. Bot. 1968, 55, 600-610. [CrossRef]

10. Ellis, R. Effects of acetate on the growth and chlorophyll content of Golenkinia. J. Phycol. 1970, 6, $364-368$. [CrossRef]

11. Ellis, R.J. Heterotrophic nutrition and its effects on chlorophyll synthesis in Golenkinia (Chlorophyceae). J. Phycol. 1977, 13, 304-306. [CrossRef]

12. Ellis, R.J. Nutrition of the green alga Golenkinia. Am. J. Bot. 1968, 55, 590-599. [CrossRef]

13. Moestrup, $\varnothing$. Observations on the fine structure of spermatozoids and vegetative cells of the green alga Golenkinia. Br. Phycol. J. 1972, 7, 169-183. [CrossRef]

14. Lemieux, C.; Vincent, A.T.; Labarre, A.; Otis, C.; Turmel, M. Chloroplast phylogenomic analysis of chlorophyte green algae identifies a novel lineage sister to the Sphaeropleales (Chlorophyceae). BMC Evol. Biol. 2015, 15, 264. [CrossRef] [PubMed]

15. Buchheim, M.; Müller, T.; Wolf, M. 18S rDNA sequence-structure phylogeny of the Chlorophyceae with special emphasis on the Sphaeropleales. Plant Gene 2017, 10, 45-50. [CrossRef]

16. Wolf, M. Phylogenetic position of the Golenkiniaceae (Chlorophyta) as inferred from 18S rDNA sequence data. Biologia 2003, 58, 433-436.

17. Park, J.H.; Choi, M.A.; Kim, Y.J.; Kim, Y.-C.; Chang, Y.K.; Jeong, K.J. Engineering of Klebsiella oxytoca for production of 2,3-butanediol via simultaneous utilization of sugars from a Golenkinia sp. hydrolysate. Bioresour. Technol. 2017, 245, 1386-1392. [CrossRef]

18. Choi, S.-A.; Choi, W.-I.; Lee, J.-S.; Kim, S.W.; Lee, G.-A.; Yun, J.; Park, J.-Y. Hydrothermal acid treatment for sugar extraction from Golenkinia sp. Bioresour. Technol. 2015, 190, 408-411. [CrossRef]

19. Joo, H.W.; Kim, Y.J.; Park, J.; Chang, Y.K. Hydrolysis of Golenkinia sp. biomass using Amberlyst 36 and nitric acid as catalysts. Algal Res. 2017, 25, 32-38. [CrossRef]

20. Hou, Q.; Cheng, J.; Nie, C.; Pei, H.; Jiang, L.; Zhang, L.; Yang, Z. Features of Golenkinia sp. and microbial fuel cells used for the treatment of anaerobically digested effluent from kitchen waste at different dilutions. Bioresour. Technol. 2017, 240, 130-136. [CrossRef]

21. Takeshita, T.; Ota, S.; Yamazaki, T.; Hirata, A.; Zachleder, V.; Kawano, S. Starch and lipid accumulation in eight strains of six Chlorella species under comparatively high light intensity and aeration culture conditions. Bioresour. Technol. 2014, 158, 127-134. [CrossRef] 
22. Peccia, J.; Haznedaroglu, B.Z.; Gutierrez, J.; Zimmerman, J.B. Nitrogen supply is an important driver of sustainable microalgae biofuel production. Trends Biotechnol. 2013, 31, 134-138. [CrossRef] [PubMed]

23. Shin, Y.S.; Choi, H.I.; Choi, J.W.; Lee, J.S.; Sung, Y.J.; Sim, S.J. Multilateral approach on enhancing economic viability of lipid production from microalgae: A review. Bioresour. Technol. 2018, 258, 335-344. [CrossRef]

24. Renuka, N.; Guldhe, A.; Singh, P.; Ansari, F.; Rawat, I.; Bux, F. Evaluating the potential of cytokinins for biomass and lipid enhancement in microalga Acutodesmus obliquus under nitrogen stress. Energy Convers. Manag. 2017, 140, 14-23. [CrossRef]

25. Verma, E.; Singh, S.; Niveshika; Mishra, A.K. Salinity-induced oxidative stress-mediated change in fatty acids composition of cyanobacterium Synechococcus sp. PCC7942. Int. J. Environ. Sci. Technol. 2019, 16, 875-886. [CrossRef]

26. Takagi, M.; Karseno; Yoshida, T. Effect of salt concentration on intracellular accumulation of lipids and triacylglyceride in marine microalgae Dunaliella cells. J. Biosci. Bioeng. 2006, 101, 223-226. [CrossRef]

27. Ji, X.; Cheng, J.; Gong, D.; Zhao, X.; Qi, Y.; Su, Y.; Ma, W. The effect of $\mathrm{NaCl}$ stress on photosynthetic efficiency and lipid production in freshwater microalga-Scenedesmus obliquus XJ002. Sci. Total Environ. 2018, 633, 593-599. [CrossRef]

28. Song, M.; Pei, H.; Hu, W.; Ma, G. Evaluation of the potential of 10 microalgal strains for biodiesel production. Bioresour. Technol. 2013, 141, 245-251. [CrossRef]

29. Pancha, I.; Chokshi, K.; George, B.; Ghosh, T.; Paliwal, C.; Maurya, R.; Mishra, S. Nitrogen stress triggered biochemical and morphological changes in the microalgae Scenedesmus sp. CCNM 1077. Bioresour. Technol. 2014, 156, 146-154. [CrossRef]

30. The State Environmental Protection Administration, Monitoring Method of Water and Wastewater; China Environmental Science Press: Beijing, China, 2002; Volume 105, pp. 246-248, 255-257.

31. Filippino, K.C.; Mulholland, M.R.; Bott, C.B. Phycoremediation strategies for rapid tertiary nutrient removal in a waste stream. Algal Res. 2015, 11, 125-133. [CrossRef]

32. Rearte, T.; Vélez, C.; Beligni, M.; Figueroa, F.D.L.; Gomez, P.; Flaig, D.; De Iorio, A. Biological characterization of a strain of Golenkinia (Chlorophyceae) with high oil and carotenoid content induced by increased salinity. Algal Res. 2018, 33, 218-230. [CrossRef]

33. Delattre, C.; Pierre, G.; Laroche, C.; Michaud, P. Production, extraction and characterization of microalgal and cyanobacterial exopolysaccharides. Biotechnol. Adv. 2016, 34, 1159-1179. [CrossRef] [PubMed]

34. Xiao, R.; Zhuang, G. Overview of microalgal extracellular polymeric substances (EPS) and their applications. Biotechnol. Adv. 2016, 34, 1225-1244. [CrossRef] [PubMed]

35. Ramanna, L.; Rawat, I.; Bux, F. Light enhancement strategies improve microalgal biomass productivity. Renew. Sustain. Energy Rev. 2017, 80, 765-773. [CrossRef]

36. Han, F.; Pei, H.; Hu, W.; Song, M.; Ma, G.; Pei, R. Optimization and lipid production enhancement of microalgae culture by efficiently changing the conditions along with the growth-state. Energy Convers. Manag. 2015, 90, 315-322. [CrossRef]

37. Liao, Q.; Sun, Y.; Huang, Y.; Xia, A.; Fu, Q.; Zhu, X. Simultaneous enhancement of Chlorella vulgaris growth and lipid accumulation through the synergy effect between light and nitrate in a planar waveguide flat-plate photobioreactor. Bioresour. Technol. 2017, 243, 528-538. [CrossRef]

38. Xia, S.; Gao, B.; Fu, J.; Xiong, J.; Zhang, C. Production of fucoxanthin, chrysolaminarin, and eicosapentaenoic acid by Odontella aurita under different nitrogen supply regimes. J. Biosci. Bioeng. 2018, 126, 723-729. [CrossRef]

39. Chokshi, K.; Pancha, I.; Ghosh, A.; Mishra, S. Salinity induced oxidative stress alters the physiological responses and improves the biofuel potential of green microalgae Acutodesmus dimorphus. Bioresour. Technol. 2017, 244, 1376-1383. [CrossRef]

40. Paliwal, C.; Mitra, M.; Bhayani, K.; Bharadwaj, S.V.; Ghosh, T.; Dubey, S.; Mishra, S. Abiotic stresses as tools for metabolites in microalgae. Bioresour. Technol. 2017, 244, 1216-1226. [CrossRef]

41. Li, Y.; Huang, J.; Sandmann, G.; Chen, F. High-light and sodium chloride stress differentially regulate the biosynthesis of astaxanthin in Chlorella zofingiensis (Chlorophyceae). J. Phycol. 2009, 45, 635-641. [CrossRef] 
42. Minhas, A.K.; Hodgson, P.; Barrow, C.J.; Sashidhar, B.; Adholeya, A. The isolation and identification of new microalgal strains producing oil and carotenoid simultaneously with biofuel potential. Bioresour. Technol. 2016, 211, 556-565. [CrossRef] [PubMed]

43. Aburai, N.; Sumida, D.; Abe, K. Effect of light level and salinity on the composition and accumulation of free and ester-type carotenoids in the aerial microalga Scenedesmus sp. (Chlorophyceae). Algal Res. 2015, 8, 30-36. [CrossRef]

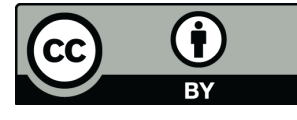

(C) 2020 by the authors. Licensee MDPI, Basel, Switzerland. This article is an open access article distributed under the terms and conditions of the Creative Commons Attribution (CC BY) license (http://creativecommons.org/licenses/by/4.0/). 